\title{
NOTAS SOBRE LA CUESTIÓN DE LA ESCLAVITUD EN LA OBRA DE GAETANO DE SANCTIS
}

\author{
Jordi Cortadella Morral* \\ Universitat Autònoma de Barcelona \\ César Sierra Martín** \\ Universitat Autònoma de Barcelona
}

\section{Овjetivo}

Con ocasión de este XXXVIII Coloquio GIREA sobre la historia de la historiografía de la esclavitud; tenemos el objetivo de explorar las obras más señeras del historiador romano para aislar su interpretación y sensibilidad hacia el problema de la esclavitud en la antigüedad. Abordaremos los siguientes casos de estudio: 1) análisis de la esclavitud por deudas y la política de Solón, considerando el Atthís: Storia della Repubblica ateniese (1898, ampliado en 1912) y 2) el supuesto affratellamento tra padroni e servi

\footnotetext{
* Proyecto HICOAN 2014 SGR 1111

** Este trabajo se ha realizado en el marco de las ayudas posdoctorales del programa Beatriu de Pinós de la Generalitat de Catalunya (2014 BP-A 00034).
} 
que se desprendería de la Ley de las XII tablas, contenido en su Storia dei romani (vol. 2,1907 ). Como podemos apreciar, son obras que nos ayudarán a captar los trazos de su hermenéutica en la antesala de la Primera guerra.

\section{GaETANo De SANCTIS: INTRODUCCIÓN BIOGRÁfica}

Gaetano De Sanctis nació en Roma el 15 de octubre de 1870, era el tercero de cuatro hermanos de una familia de profundas convicciones católicas al servicio del Estado vaticano. Su padre, Ignazio De Sanctis, era teniente de la Guardia di Finanza vaticana y su abuelo trabajó como secretario general de la administración de sales y tabacos. Pocas semanas antes del nacimiento de Gaetano se produjo la breccia di Porta Pia (20 septiembre 1870), momento en que las tropas italianas derrocaban el gobierno de Pío $\mathrm{IX}^{1}$. Como detalla De Sanctis en sus memorias, la incorporación del Estado Vaticano a la Italia unificada supuso un duro golpe para su familia. Tras la caída de Roma, al padre le ofrecieron la posibilidad de continuar su carrera si juraba fidelidad a la monarquía italiana pero rechazó la propuesta por principios morales: los De Sanctis eran «vaticanistas» y ya habían jurado fidelidad al Papa. Pese a la pérdida del empleo, la familia mantuvo un cierto estatus gracias a la generosa paga de jubilación del abuelo $^{2}$. A partir del fallecimiento de éste, se trasladaron a una vivienda más modesta mientras el padre aceptó un mal remunerado cargo de scrivano avventizio. Una situación desagradable para una familia que entendía la sociedad de forma estratificada según las posibilidades económicas: asalariados, pequeña burguesía, alta burguesía o profesionales liberales y señores rentistas. La relación entre clases debía ser distante y sin interacción ${ }^{3}$. Con todo, al jovencísimo Gaetano no le faltó una magnífica educación en el colegio y liceo de la que guardó buenos recuerdos. En 1888 se inscribió en la Facultad de Filosofía y Letras de Roma, donde cuatro años después obtuvo la licenciatura con una tesis titulada: Contributi alla storia ateniese dalla guerra lamiaca alla guerra cremonidea (1892); dirigida por su maestro Karl Julius Beloch. Tras dos años de especialización en Roma, en 1895 tomó contacto con la arqueología en diversas excavaciones de la zona occidental de Creta, bajo protectorado italiano tras la expulsión de las fuerzas turcas. En Grecia conoció a otros historiadores ilustres de su época como Mikhail Rostovtzeff y Wilhelm Dörpfeld. En 1897 obtuvo un encargo de libera

1. M. Berti; V. Costa, "Introduzione”, en G. De sanctis, Filippo e Alessandro dal regno macedone alla monarchia universale, Roma 2011, v.

2. G. De Sanctis, Ricordi della mia vita, a cura di S. Accame, Firenze 1970, 16-17.

3. Véase el detalle en De Sanctis, Ricordi... op. cit., 30. 
docenza en Padua pero el concurso resultó anulado en extrañas y no esclarecidas circunstancias 4 . En 1898 publicó una primera versión de su Atthís: Storia della Repubblica ateniese, una obra de amplio calado cronológico que abarca desde la prehistoria griega hasta el gobierno de Clístenes, que se reeditó y amplió en 1912 hasta el cénit ateniense en época de Pericles ${ }^{5}$. En 1900 obtuvo la cátedra de historia antigua en la universidad de Turín, superando en el concurso a su rival Ettore Pais. Poco después, en 1907, comenzó su monumental Storia dei romani, cuyo último volumen se publicará póstumamente ${ }^{6}$. En Turín permanecerá varias décadas enseñando y formando a gran parte de su escuela, particularmente A. Ferrabino, A. Rostagni y M. A. Levi.

En marzo de 1918, De Sanctis se presentó como candidato a la sucesión de su maestro en la cátedra de Roma ${ }^{7}$. En primera instancia ganó el concurso pero, tras una deliberación del consejo de facultad, los votos se decantaron finalmente hacia Ettore Pais ${ }^{8}$. A partir de entonces, la relación entre De Sanctis y Pais se puede definir sin lugar a dudas como un antagonismo personal. Con todo, en 1929 De Sanctis volvió a Roma para, esta vez sí, suceder a Beloch en la cátedra de historia griega. En ese momento se llevó a Roma a sus dos mejores alumnos: Arnaldo Momigliano y Piero Treves9. Pocos años después, el 28 de agosto de 1931, se repetía en él la historia de su

4. Bibliografía en Berti y Costa, “Introduzione...”, op. cit., vi.

5. Se publicó una tercera edición con material inédito del autor y una interesante introducción de Silvio Accame, que sintetiza muy bien la trayectoria y recepción del libro; S. Accame, "Premessa”, en Gaetano De Sanctis, Atthís. Storia della Repubblica ateniese dalle origini alla età di Pericle, Firenze, 1975, ix-xxxviii. Más datos en D. Erdas, "Introduzione”, en G. De Sanctis, Pericle, Roma, 2011, v.

6. G. De Sanctis, Storia dei Romani: I. Roma dalle origini alla monarchia, Milano-Torino, 1906 / II. La conquista del primato in Italia, Milano-Torino, 1907 / III.1. L'età delle guerre puniche, Milano-Torino, 1916 / III.2. L'età delle guerre puniche, Milano-Torino, 1917 / IV.1. La fondazione dell' Impero: dalla battaglia di Naraggara alla battaglia di Pidna. Milano-Torino, 1923 / IV.2.1. Vita e pensiero nell'età delle grandi conquiste. Firenze, 1953 / IV.2.2. Dal diritto quiritario al diritto pretorio. Firenze, 1957 / IV.3. Dalla battaglia di Pidna alla caduta di Numanzia. Firenze, 1965.

7. K. Julius Beloch, que mantuvo la ciudadanía alemana, fue expulsado de su cargo tras la derrota italiana en Caporetto durante la Primera Guerra Mundial. Posteriormente fue confinado en Siena; Berti y Costa, "Introduzione..., op. cit., x.

8. Según de De Sanctis, una entente entre Pais y el ministro Berenini consiguió expulsar a K.J. Beloch tras el desastre de Caporetto; De Sanctis, Ricordi... op. cit., 125. Obviamente la vacante tenía dueño.

9. Mientras, la enemistad con Ettore Pais continuaba. Según Piero Treves, durante la década de los treinta Pais boicoteaba sistemáticamente las clases de De Sanctis en Roma; vid. D. Musti, "Gaetano De Sanctis tra biografia e studi", Rivista di Filologia e di Istruzione Classica, 141, 2013, 407. 
padre: por principios morales rechazó firmar el manifiesto de adhesión al régimen fascista auspiciado por Giovanni Gentile. Las consecuencias fueron desastrosas ya que perdió la cátedra y fue excluido de los principales organismos culturales italianos. Desde 1931 hasta 1944 no recibió ningún encargo docente, ni sustento económico alguno y a todo ello debemos sumar la enfermedad ocular que padecía (glaucoma), que lo dejó totalmente ciego. Todo ello no impidió que en 1934 fuese nombrado profesor honoris causa por la Universidad de París (Sorbona), sumándose a idénticos honores concedidos previamente en Oxford (1925), Universidad católica de Lovaina (1927) y Cambridge $(1930)^{10}$. Sin duda De Sanctis fue una figura de proyección internacional. Tras la guerra y la caída del régimen fascista, De Sanctis fue rehabilitado de por vida en su cargo, llegando a la política como senador en 1950. Siete años después falleció en Roma, el 9 de abril de 1957.

\section{SOLÓN, ENTRE LA MASA INCULTA Y LA ARISTOCRACIA OPRESORA}

A partir del sexto capítulo del Atthís titulado: Solone e le sue riforme económicosociali, De Sanctis expone su predilección por aquellos líderes políticos moderados, honestos y sacrificados por el pueblo. En concreto, se muestra muy partidario de la acción política de Solón cuya labor define globalmente como favorable al pueblo. En concreto, entiende la supresión de la esclavitud por deudas como un acto de justicia social ${ }^{11}$. No obstante, secunda estas reformas sociales siempre dentro de unos límites bien definidos; por este motivo censura la redistribución de tierras, calificándola de revolucionaria ${ }^{12}$. No duda, en este contexto, en utilizar conceptos sociológicos modernos para designar realidades de la Antigüedad tales como revolución, burguesía, proletariado, etc ${ }^{13}$.

En general, el esquema social que plantea De Sanctis para la Atenas soloniana es sencillo y conocido: por un lado, había una oligarquía voraz y opresora que sentaba las bases para la aparición de la tiranía y, por otro, un pueblo ateniense inmaduro

10. Más datos en Berti y Costa, "Introduzione..., op. cit., x.

11. G. De Sanctis, Atthís: storia della Repubblica ateniese dalle origini alla età di Pericle, Torino, 1912 (1963), 206-207.

12. De Sanctis, Atthís... op. cit., 206.

13. En sus memorias, el historiador rechazará abiertamente las corrientes intelectuales afines a los movimientos obreros; De Sanctis, Ricordi... op. cit., 145. Véase también la opinión que le merecían marxistas como Ettore Ciccotti, criticado durante el discurso inaugural del año académico 1904-1905 en la Universidad de Turín, con título: La guerra e la pace nell’antichità; G. De Sanctis, “La Guerra e la Pace nell'Antichità, en Scritti minori, v. 3, Roma, 1904 (1972), 203-204. 
para asumir la dirección política ${ }^{14}$. Por encima de este esquema se alzaba la figura brillante de Solón, con un liderazgo ecuánime. Según De Sanctis, la integridad de Solón le impidió aceptar la tiranía y ello condujo a un vacío de poder que derivó en la anarquía. En esta tesitura se alzaron líderes decididos a capitalizar el descontento del pueblo. Sobre este particular De Sanctis realiza una interesante analogía entre política antigua y moderna en relación al origen social de los tiranos griegos:

Come i capi del partito socialista odierno, che avversa e combatte la borghesia, sono in massima borghesi, così i capi dei popolari ateniesi erano aristocratici ${ }^{15}$.

Así pues, llega a la conclusión que los tiranos son aristócratas arrepentidos así como los socialistas de la época - para de De Sanctis- eran burgueses descontentos. Se desprende de este argumento que, en ambos casos, se trata de oportunistas que de recibir un trato igualitario entre sus colegas no se pondrían al frente de los movimientos populares ${ }^{16}$. Abundando sobre la tiranía, su juicio sobre Pisísitrato no es adverso y destaca aquellas medidas que sentaron los cimientos de la futura potencia ateniense ${ }^{17}$. La percepción del proceso histórico desde Pisístrato hasta Clístenes se resume así como una adquisición progresiva de poder por parte del dêmos. Un dêmos que comenzaría a tomar conciencia de su rol político. No obstante, la determinación del pueblo ateniense en su reclamación de derechos requirió de un político audaz e innovador como Clístenes ${ }^{18}$. De Sanctis destaca como un acierto particular la institución de la boulé, entendiéndola como instrumento que limitaba el gran poder que el dêmos estaba adquiriendo e impedía que la clase acomodada fuera tiranizada por las clases pobres, los thêtes. En sintonía con lo anterior, se muestra absolutamente en contra del ostracismo, según él un mecanismo arbitrario para eliminar a los rivales

14. Nótese como De Sanctis plantea la adquisición de los derechos civiles como una concesión del legislador no como una conquista del pueblo; De Sanctis, Atthís... op. cit., 258.

15. De Sanctis, Atthís... op. cit., 268.

16. La visión del tirano como tutor de un pueblo inmaduro y como político oportunista ha gozado de notable éxito en la historiografía moderna. En nuestro caso hemos estudiado el ejemplo de Lígdamis de Naxos (c. 540 a.C.); C. Sierra, J. Cortadella, “Telestágoras y la instauración de la tiranía en Naxos", Rivista di Cultura Classica e Medioevale, 54, 2012, 241-255.

17. Especialmente con la adopción de una política marítima que aumentó las posibilidades económicas; De Sanctis, Atthís... op. cit., 314.

18. Solón no introdujo muchas novedades, solo puso por escrito la tradición con la intención de frenar los abusos contra el pueblo; De Sanctis, Atthís... op. cit., 357. 
políticos y que nada tenía que ver con los principios de justicia y libertad ${ }^{19}$. Por eso aprecia que los thêtes en esa época no pudieran acceder a la boulé, retomando la idea de las reformas dentro de unos límites. El universo espiritual de De Sanctis aflora en esta concepción social, a saber: los abusos entre clases son reprobables y deben corregirse pero se debe mantener la estratificación social. Un status quo que necesitaba de un recorte de derechos para ser un governo libero, entendiéndose la libertad como ausencia de abusos y conflictos ${ }^{20}$.

Por tanto, la visión de Gaetano De Sanctis sobre la esclavitud antigua está condicionada por la interpretación de la sociedad bajo este prisma. Partiendo de este contexto, la clave de la conflictividad social en la Atenas del siglo VI a.C. estaba en la opresión que sufrían los pequeños propietarios. Los poderosos monopolizaban el poder y no se conformaban con obtener grandes beneficios sino que hacían todavía más asfixiante la situación de los débiles. El argumento queda bien resumido en el siguiente testimonio:

I signori, anzichè godersi a tranquilla mensa le loro ricchezze, rubano a man salva $\mathrm{e}$ di ciò che è sacro e di ciò che è pubblico: oppressione insopportabile donde nascerà la tirannide ${ }^{21}$.

Los pequeños propietarios eran, para De Sanctis, el eslabón más débil de la economía, aquellos que sufrían más las consecuencias de las malas cosechas, los imprevistos climáticos o las coyunturas económicas adversas. Por este motivo, los propietarios se veían obligados a endeudarse con los poderosos, quienes reclamaban un aval elevadísimo con el consiguiente aumento del clientelismo y la esclavitud. En este sencillo esquema podemos entrever la moralidad cristiana en torno a la usura, además de una actitud caritativa hacia los desfavorecidos pero siempre moviéndonos en la esfera de la ciudadanía ateniense, sin entrar a valorar otras figuras sociales como metecos y esclavos de procedencia extranjera.

Como sabemos, los pequeños campesinos llegaron a poner como garantía su persona y su familia. Sobre este complicado panorama emergen figuras que en De Sanctis toman el valor de «árbitros»; políticos moralmente comprometidos con la comunidad que tienen como objetivo paliar los abusos de la aristocracia. Así pues,

19. Se trata de una mostruosità giuridica aprobada por miedo a la tiranía y al servicio de la lucha política entre cabezas de partido; De Sanctis, Atthís... op. cit., 370-371.

20. No es una idea que debamos tomar como un cuadro fijo ya que muchos de los argumentos del Atthís se matizan o incluso abandonan en Storia dei Greci de 1942.

21. De Sanctis, Atthís... op. cit., 197. 
Solón adquiere en la obra de De Sanctis un aura paternal para el dêmos ateniense, que puede aspirar a que sus derechos se vean respetados sin recurrir a la conjura política. Tanto en Atthís como en Storia dei Greci, Solón es definido como un legislador que aprovecha la tradición política; una persona que exigía cumplir el marco político y legal existente. Todo ello queda bien glosado en el siguiente testimonio:

[Solón] Al popolo faceva balenare intanto la speranza che sarebbero cessati i suoi mali, ma non per via delle congiure, donde poteva nascere invece il servaggio di tutti ad un solo [la tiranía] e le lote sanguinose tra cittadini, sì mercè l'ordine e le buone leggi ${ }^{22}$.

En De Sanctis hay un claro componente de moderación en la búsqueda de soluciones políticas a los males sociales. En este sentido, el pueblo debería dejarse guiar por políticos con arrojo, determinación y valía. La peculiaridad de este planteamiento estriba en que De Sanctis no parte del análisis de las condiciones económicas, jurídicas y sociales de los desfavorecidos; ni tampoco enumera y desarrolla en extensión las diferentes categorías jurídicas, en cambio sí desarrolla las características de las clases censitarias... Se trata de un planteamiento entre ricos y pobres, donde los primeros oprimen injustamente a los segundos. Ahora bien, la población desfavorecida e inculta no estaría preparada para tomar las riendas del Estado y ejercer activamente sus derechos políticos ${ }^{23}$. La ponderación, para De Sanctis, estaba en la clase media, los zeugitas, que sí merecían el pleno acceso a las magistraturas, la asamblea, el tribunal popular, etc.

Sin embargo, pronto este sistema político equilibrado propuesto por Solón y mejorado por Clístenes se habría corrompido. El historiador desarrolla esta idea en la versión ampliada del Atthís (1912), donde identifica en Pericles al líder que dará la oportunidad de participar en los asuntos públicos a personas incultas y humildes. De este modo, en el doceavo capítulo titulado: Pericle e la vittoria dei popolari, comienza una dura crítica contra su acción de gobierno. Desde el principio, el autor plantea que el misthós, o paga por prestar servicios al Estado, es un elemento corruptor de la democracia ${ }^{24}$. Asimismo, la acusación pública judicial, sin control del Areópago, habría propiciado la aparición de los acusadores profesionales, los sicofantes. En la misma línea, desde las reformas de Efialtes, la boulé estaría abierta a todos los ciudadanos y tendría un amplio poder coercitivo que degeneró, según De Sanctis, en injusticia y

22. De Sanctis, Atthís... op. cit., 203.

23. De Sanctis, Atthís... op. cit., 258.

24. De Sanctis, Atthís... op. cit., 416, con severas críticas a la política de Pericles. 
caos. Todas estas reformas promovidas por Efialtes y luego por Pericles habrían otorgado un poder al pueblo que rompía con esa idea de equilibrio conseguida por Solón y Clístenes. La responsabilidad recae de nuevo en la ignorancia de la clase humilde, llegando incluso al prejuicio. Véanse, si no, las impresiones de De Sanctis sobre el mal funcionamiento del tribunal popular o heliaía: «Ma al posto della corruzione individuale la ignoranza e la povertà dei giurati aprivano il varco alla corruzione e al favoritismo colletivo» ${ }^{25}$.

La situación se extiende y se agrava alrededor de la misthophoría como elemento clave de la degeneración de la democracia, merece la pena prestar atención al siguiente extracto:

[...] La paga eliastica costituiva pel bilancio cittadino uno dei maggiori aggravî e così uno degli incentivi maggiori a iniquità di confische [...] la paga costituiva un richiamo per quelli che non possedevano nulla e non avevano lavoro o volontà di cercarne [...] ma in qualque modo distoglieva dal partecipare alla giura chi aveva coltura e denari; perchè se pur superava la ripugnanza al contatto troppo inmediato e frequente con uomini della clase inferiore, non era facile che superasse quella a veder sopraffatto il proprio giudizio e il proprio voto dal voto della maggioranza non colta ${ }^{26}$.

Se trata sin duda de un juicio de valor que asocia de forma inherente la pobreza con la corrupción. Siguiendo el texto, la misthophoría era la miel de los pobres incultos que no tenían trabajo ni volontà di cercarne, que se opone a aquellos que, por tener dinero, poseían mayor cultura. Unos estaban preparados para participar en la política y otros no ${ }^{27}$. Esta nos parece una opinión claramente clasista aunque propia del momento en el que fue escrita la obra ${ }^{28}$. Sobre este particular téngase en cuenta que el rechazo de las élites intelectuales hacia las masas partía ya del pensamiento

25. De Sanctis, Atthís... op. cit., 449.

26. De Sanctis, Atthís... op. cit., 453.

27. Al margen de la opinión que en este capítulo vierte De Sanctis, lo cierto es el misthós fue un elemento de redistribución pública de los recursos que influyó de forma notoria en la relación entre clases acomodadas y clases pobres. Como sugiere Domingo Plácido, para que el misthós existiera se requería la exacción tributaria a los aliados y la participación en la vida pública de las clases adineradas; sin duda un delicado equilibrio. Véase D. Plácido, "La expedición a Sicilia (Tucídides, VI-VII): métodos literarios y percepción del cambio social”, Polis, 5, 1993, 202-203.

28. Este proceso denigratorio de la democracia ateniense parte de la Antigüedad, cuando los sectores oligárquicos de Atenas cargaron la culpa sobre el dêmos de la derrota en la guerra del Peloponeso. En aquellos momentos se optó por un retorno simbólico a la 'constitución ancestral', la pátrios politeía, situando a Solón como referencia. Sobre esta cuestión todavía resulta excepcional 
político del siglo XIX y cristalizó en conceptos como el de Tyrannie de la majorité de Alexis de Tocqueville, seguido en lo esencial por el Tyranny of the majority de John Stuart Mill o el imperio de las masas de José Ortega y Gasset ${ }^{29}$. Para De Sanctis, la trayectoria política del pueblo ateniense trascendía la lucha por los derechos políticos y se adentraba en el terreno moral. Era una agresión contra la población culta:

[...] il fervore per la democrazia non era stato ancora smorzato dagli abusi dei tribunal democratici e dalla ribellione morale degli intelligenti contro la tirannide della moltitudini incolte e passionate ${ }^{30}$.

La conexión con las ideas de A. de Tocqueville es notoria y sitúa a De Sanctis en una corriente elitista propia de inicios del siglo XX. El tono contra el pueblo humilde reincide sobre la idea de que era un agente político que debía ser controlado porque era inculto e irreflexivo ${ }^{31}$. Sin duda es una perspectiva paternalista de la democracia antigua (y de la moderna) que De Sanctis desarrolla desde Solón y que tras las guerras médicas llegará a su máxima expresión con la denominada democracia radical. Para De Sanctis, la democracia de Efialtes y Pericles representó el retorno a una tendencia disgregadora, negativa, con claras simpatías por el subsidio (Tendenzia parasitaria); incapaz de extender la ciudadanía al resto de aliados, como hizo Roma, y liderar la lucha contra Persia ${ }^{32}$. Sin embargo, esta inicial posición elitista en De Sanctis quedará matizada pocos años más tarde, en un artículo de 1924 titulado Da Clistene a Temistocle donde se rebaja sustancialmente el tono. Aquí desaparece la teoría del dêmos parasitario y se identifica dicha interpretación con una corriente antidemocrática protagonizada por el pseudo-Jenofonte y Aristóteles ${ }^{33}$. Por otro lado, en Storia dei Greci (1942), el historiador aborda temas tratados en Atthís desde un

la aproximación de M.I. Finley, "La costituzione degli antenati", en Id., Uso e abuso della storia, Torino, 1975 (1981), 39-83.

29. Respectivamente, A. de Tocqueville, De la Démocratie en Amérique, Paris, 1864 (1961), 261; J.S. Mill, On Liberty. with The Subjection of Women and a Chapter on Socialism, Cambridge, 1856 (1989), 8 y J. Ortega y Gasset, La rebelión de las masas, Madrid, 1929 (2002), 54. Amplíese la información en D. Villa, Socratic Citizenship, Princeton, 2001.

30. De Sanctis, Atthís... op. cit., 395.

31. El historiador reconoce en sus memorias que su familia desaprobaba que las clases desfavorecidas aprendieran a leer y reclamaran más derechos cívicos; De Sanctis, Ricordi... op. cit., 30.

32. De Sanctis, Atthís... op. cit., 471-473.

33. Tendencia que toma expresión en República de los atenienses y Constitución de los atenienses, respectivamente; G. De Sanctis "Da Clistene a Temistocle", Rivista di filología classica 2, 289-306, en Scritti minori, v. 1, Roma 1924 (1970), 55. 
tono más comprensivo y favorable a la adquisición de derechos políticos por parte del pueblo. Asimismo, Storia dei greci retoma la valoración positiva de Solón y Clístenes añadiendo una imagen más ecuánime de Pericles ${ }^{34}$.

Como primera conclusión de nuestro trabajo, sugerimos que no hubo en De Sanctis un interés por articular un análisis global de la esclavitud en el mundo antiguo. En el caso concreto de la esclavitud por deudas, apreciamos dos facetas: 1) censura por la pérdida de derechos políticos de los ciudadanos pobres, y 2) la inmoralidad de las clases dirigentes al beneficiarse del sufrimiento ajeno. La superación del problema no es abordada desde la lucha política sino a partir de la aplicación de leyes ya existentes («buenas leyes»). De Sanctis, partidario de una democracia tutelada por una aristocracia justa, nada dijo de la población no ateniense esclavizada porque en nada afectaba, según él, a la estabilidad política del Estado.

\section{LA CIUDADANÍA DE LOS LIBERTOS}

El mismo recelo que De Sanctis muestra hacia los ciudadanos pobres de Atenas, aparece en su Storia del romani respecto a los esclavos que obtienen la ciudadanía romana, y por motivos parecidos. Así pues, según él, la democracia romana quería mantenerse pura del dudoso elemento de los libertos: " al modo stesso che nella America del nord i socialisti sono i primi a voler proteggere con barriere artificiali $i$ lavoratori indigeni contro la concorrenza degli emigranti» ${ }^{35}$. Y añade que ningún otro Estado antiguo era tan liberal hacia los esclavos manumitidos como la oligarquía romana; y no todos los Estados modernos serán tan liberales hacia los inmigrantes extranjeros y hacia los nativos di colore. Para De Sanctis, por tanto, el aparente estado de inferioridad al que se sometió a gran parte de los libertos en comparación con los otros ciudadanos solo servía para evitar que aquellos se valiesen de la paridad de derechos para avasallar los derechos de los demás ${ }^{36}$. La comparación de los derechos políticos de los antiguos libertos, en Roma, con la de los modernos emigrantes (italianos), en Norteamérica, hace que De Sanctis vea a los libertos de un modo ambivalente, como un elemento nuevo, capaz, atrevido, de cuyos intereses y cuyas aspiraciones toda política realista debía tener en cuenta.

34. Ni qué decir tiene que este cambio de enfoque es debido a la experiencia vital del propio autor en la Italia fascista.

35. G. De Sanctis, Storia dei romani. IV La fondazione dell' impero. Parte I, Dalla battaglia di Naraggara alla battaglia di Pidna, Milano-Torino 1923, 557.

36. De Sanctis, storia dei romani... op. cit., 558. 
Con el idealismo propio de la filosofía de la historia aprendida de sus maestros, De Sanctis creía que con la ciudadanía de los libertos, si por un lado la Justicia que actuaba en la Historia compensaba a los antiguos esclavos de la violencia por la cual ellos o sus padres habían perdido su libertad, por otro lado la justicia histórica castigaba a los que con la violencia los habían arrebatado de la patria y de la familia, insiriendo entre los conquistadores romanos un elemento que debilitaba y dañaba su estructura étnica y que, sobre todo cuando mayor fue la afluencia de esclavos en Roma (entre la primera mitad del siglo II. aC y la época entorno a Nerón), contribuyeron claramente a la decadencia de la vida política en la ciudad de Roma y en la República en general ${ }^{37}$.

Había en De Sanctis desconfianza, miedo, recelo ante los que él califica de verdaderos desarraigados a cuya elevación moral no habían contribuido en nada las experiencias en el mercado de esclavos y el ergástulo, la cadena y el látigo; y que aparecían, con razón o sin ella, a los auténticos Quirites como «poco deseables», del mismo modo -añade-como a los norteamericanos aparecen: "gli emigranti di stirpi troppo diverse dalla anglosassone». Sin embargo -concluye de manera ambivalente- en esta clase inquieta y descontenta, si la reacción podía encontrar sus secuaces mercenarios y su bestiame da voto; también la revolución, si hubiese podido superar los antiguos egoísmos y sobre todo la visión unilateral de los intereses agrarios y el prejuicio hacia todo lo que no era romano en Roma, habría hallado aliados, comprometedores y peligrosos ciertamente pero válidos para el éxito ${ }^{38}$.

Observamos pues un mismo desinterés en De Sanctis por articular un análisis global de la esclavitud. En el caso concreto de la manumisión en Roma, apreciamos también dos facetas: 1) censura por la concesión de derechos políticos a los libertos, y 2) incapacidad moral de la clase dirigente romana por integrar a los elementos más validos de estos nuevos ciudadanos y asegurar así la estabilidad política del Estado.

En última instancia, De Sanctis aceptaba la esclavitud como parte inevitable de un estadio de civilización en el que el sentido jurídico y moral aún no había progresado lo suficiente, además de un instrumento para superar la poligamia, pues el desarrollo de la esclavitud: «permetteva di soddisfare con minore spesa e minori formalità, in quanto non s'appagavano nella famiglia, gl' istinti sessuali» ${ }^{39}$.

37. De Sanctis, storia dei romani... op. cit., 559.

38. De Sanctis, storia dei romani... op. cit., 560.

39. G. De Sanctis, Storia dei romani. I La conquista del primato in italia, Milano-Torino, 1907, 82. 


\section{CONCLUSIONES}

La lectura de Atthís y de la Storia dei romani arroja unas conclusiones interesantes como son la ausencia de una interpretación detallada y global del fenómeno de la esclavitud en el mundo antiguo por parte de De Sanctis. Al respecto, hemos hablado siempre de cómo De Sanctis interpretó la esclavitud por deudas como resultado de la opresión de los aristócratas. No obstante, ¿Qué hay del resto de los esclavos? Obviamente De Sanctis no se ocupó de los esclavos bárbaros; ni abordó las consecuencias del trabajo esclavo a gran escala. Quizás el punto neurálgico de todo ello sea la concepción fuertemente etnocéntrica que desarrolló, con los griegos como sustrato primigenio de la cultura occidental ${ }^{40}$. En relación con lo anterior, debemos mencionar su conocida postura sobre el proceso colonizador europeo de África, que se resume en su apoyo a la colonización italiana de Libia y otros territorios ${ }^{41}$. La cuestión de la protección de la ciudadanía ronda continuamente la interpretación del historiador. Se trata de un concepto de ciudadano que debe ser blindado respecto a las influencias externas pero protegido y respetado desde dentro.

Así, encontramos diferentes elementos que condicionan la interpretación de De Sanctis sobre la esclavitud: la moralidad cristiana, el apoyo al colonialismo y el rechazo a los movimientos socialistas y marxistas (por su declarado anticlericalismo). Todo ello se concreta en esta interpretación paternal de la esclavitud bajo el prisma del humanismo cristiano; esclavitud censurable si afectaba únicamente a los ciudadanos, unido al temor de que antiguos esclavos (ahora libertos) desvirtúen el derecho a la ciudadanía.

40. G. De Sanctis, “La guerra e la pace..., op. cit., 204.

41. Reflejado en P. Treves, "Gaetano De sanctis", en Dizionario biografico degli italiani, v. 39, 1991, 297-309. 